\title{
Study on Problems and Countermeasures of Industrial Development of Paris in Yunnan Province
}

\author{
QI Jianling, REN Peixing \\ College of Economics and Management \\ Yunnan Agricultural University \\ Kunming, China
}

\author{
LU Yingchun* \\ Section of State-owned Assets Management \\ Yunnan Agricultural University \\ Kunming, China
}

\author{
YANG Shengchao \\ Research Office \\ Yunnan Agricultural University \\ Kunming, China
}

\begin{abstract}
Over the last decade, Paris planting industry developed very fast, and played a big role in driving rural economic development in Yunnan province as well as solving the employment problem of surplus rural labor force. The standing and function of Paris industry appears more and more prominent in traditional Chinese medicine industry of Yunnan province, and becomes an important role of traditional Chinese medicine industry of Yunnan province. Paris is in short supply on the market because of its long growth period. This paper deeply analyzed the status quo and problems of Paris industry in Yunnan province for its healthy development, and gave advice and countermeasures for optimizing Paris industry development of Yunnan province. These could have certain significance in development of Paris industry and traditional Chinese medicine industry in China.
\end{abstract}

Keywords-Paris; traditional Chinese medicinal materials; traditional Chinese medicine industry

\section{INTRODUCTION}

As an important traditional Chinese medicinal material, Paris is used as medicine by its underground stem tubers. [1] Modern medicine proves that Paris possesses efficacy of clearing heat and detoxicating and medicinal value of anticancer, antiviral, antimicrobic, analgesic, sedative, antitussive, asthma reducing, and haemostatic etc. At present stage, only Paris polyphylla Smith var. yunnanensis and Paris. Polyphylla var. chinensis in Paris genus are listed in Pharmacopoeia of People's Republic of China. Most other species could only be used as Paris medicinal materials. It usually takes 6 to 7 years for its growth period which is from the seed stage to the plant stage with blossom and fruit.

Characteristic value and unique effect of wild Paris are popular with the market all the time. Plant area of Paris in China is distributed in Yunnan province, Sichuan province, Guizhou province, Hunan province, Hubei province, Fujian province etc. There are very rich resources and the largest planting scale of Paris in Yunnan province. The time of developing artificial planting is the earliest, and the production technique is the most mature here. Therefore, both the genuine producing area and the largest production area of Paris are in Yunnan Province. In the past, Paris medicinal materials of Yunnan Province could basically satisfy the demand of market as rely on wild collection. However, with the development of new products like Gongxuening, antiviral granule, the market demand of Paris is becoming larger and larger. Especially after the SARA event in 2003, the Paris demand increases constantly with a situation of Paris resources shortage. The price of Paris medical material increases immediately. Thus, the Paris planting industry in Yunnan province quickly developed. Paris planting has already become one of the important and effective ways to get rid of poverty and become better off for some of peasant family in mountainous area of Yunnan province. [2]

\section{STATUS QUO OF INDUSTRY DEVELOPMENT}

In recent years, there are above 1200 Paris planting and breeding companies with considerable scale in Yunnan province. The planting area of Paris in Yunnan province reached $69.07 \mathrm{~km} 2$ in 2016, and it promoted employment of almost 150 thousand people. Paris planting industry became a dark horse in traditional Chinese medicinal materials industry in Yunnan province. Paris is local advanced medicinal materials in Yunnan province, and its planting pattern includes interplantation in forest, scattered family cultivation, wildlife tending, and artificial planting with shade shed building after almost ten-year exploration. The production of Paris industry in Yunnan province has following characteristics:

1) Explosive increase of planting area. Statistically, Paris planting area is $0.33 \mathrm{~km} 2$ in 2002, and it became $1.47 \mathrm{~km} 2$ in 2007 in Yunnan province. With the increasing market demand and price, the planting area of Paris polyphylla Smith var. 
yunnanensis reached $69.07 \mathrm{~km} 2$ in 2016. The planting area increased almost $500 \%$ in the decade.

2) Growing up of advanced planting area. The survey shows the centralized advanced Paris planting areas respectively are Lijiang autonomous county, Dali Bai autonomous prefecture, Zhaotong city, Salween area.

3) Advantage establishment of Paris breeds. The climate condition of Yunnan province provides advantages for Paris growth. Only Paris root Yunnanensis: Paris. Polyphylla var. chinensis is listed in Pharmacopoeia of People's Republic of China. Therefore, in the actual cultivation, most areas mainly cultivate Paris Yunnanensis or Paris vietnamensis with Paris. Polyphylla var. chinensis which meets the standard of local medicinal materials in Yunnan province, as the following picture shows. Advanced breeds is establishing step by step.

4) Large market demand of Paris. According to investigation, the usage amount of Paris in Yunnan Baiyao reached above 1000 ton each year. Paris market demand is in a rapid increase in recent ten years. However, wild Paris resources are decreasing. Paris growth period is long. Thus, the price of Paris constantly increases. With the improvement of processing technology, new products which use Paris polyphylla Smith var. yunnanensis as raw material will constantly appear.

5) Wide breeds of traditional Chinese medicines which use Paris as the raw material. Recently, traditional Chinese medicines which use Paris as the raw material are becoming more and more. Statistically, in China national medicines standard, there are above 100 varieties of Chinese patent medicines which use Paris as the raw material. Therein, traditional Chinese medicines specifically protected by China are above 20 like Yunnan Baiyao series, Gongxuening, antiviral granule series, Jinpin swelling series, and Jidesheng Sheyao tablets. All of their raw material is from Paris.

6) High output value of Yunnan Baiyao series products which use Paris as raw material.

Acquisition of almost all Paris in Yunnan province is finished by YUNNAN BAIYAO group. At present, YUNNAN BAIYAO group involves areas like traditional Chinese medicine and western medicine materials and their prepatations, personal care products, original medicinal materials, and it takes products of Yunnan Baiyao series and natural medicine series as the primary key. The annual revenue and profit of YUNNAN BAIYAO group in recent years basically keep the increase of above $20 \%$. Annual accumulated operating revenue of YUNNAN BAIYAO group is 24.315 billion yuan in 2017. Besides, the gross margin of Yunnan Baiyao series products which use Paris as raw material is the highest.

\section{PROBLEMS OF INDUSTRIAL DEVELOPMENT}

Paris industry of Yunnan province develops well. However, during the industry development, problems still exist as followings:

1) Lack of reasonable protection for wild Paris resources. For a long time, wild Paris resources constantly decrease in recent 30 years without reasonable plan and timely protection for it. Wild Paris producing areas fall into a vicious circle of "more digging, less resources; less resources, more expensive; more expensive, more digging”. Thus, Wild Paris germ-plasm resources with low propagative coefficient lost germ-plasm resources heredity, and are depleting because of lacking time to rehabilitate. Then, many breeds of Paris are about to extinct.

2) Lack of quality control standard, irregular market order. Different Paris has different usage because of difference of chemical components. Paris Yunnanensis includes flour Paris and glial Paris. Flour Paris Yunnanensis mainly used in Yunnan Baiyao, and glial Paris mainly used in Gongxuening. Paris. Polyphylla var. chinensis mainly used in Chinese patent medicines like Jidesheng Sheyao tablets.Traditional market usually accepts flour Paris as a better medicinal value, and glial Paris is secondary. Thus, the glial Paris is not popular with the market. It's difficult to have a scientific classification and evaluation for Paris because of lacking relevant quality control standard. The market order of medicinal materials is imperfect.

3) Less of scale planting area. Investment of Paris planting is large, and Paris provenance is varied. Therefore, it's difficult for seed selection. Besides, Paris grows slowly with a long growth period and low breeding capability. In addition, the proportion of mountainous area in Yunnan province is large with little barrage area. Paris scale planting has a very high requirement for soil and infrastructure. Peasant household in many areas plants Paris in small scale. Foundation scale planting areas are less.

4) Insufficient fundamental study investment and lagging scientific study. Chemical components of Paris are directly related to its therapeutic effects. Clear analysis on effects of all kinds of Paris resources can provide more medicinal resources for Chinese medicine. Recent years, there is a series of scientific achievements in the production and development of biologics resources under the active study for traditional Chinese medicine of National Engineering Research Center for traditional Chinese medicinal material germ plasm innovation and utilization in Yunnan Agricultural University, Yunnan Branch of The Institute of Medicinal Plant Development, and Kunming Institute of Botany, Chinese Academy of Sciences. However, problems like less scientific investment, lack of core technology, and low technology content still exist.

5) Lack of hi-tech talents of the industry. Recently, top talents who major in Paris seed cultivation, planting, processing and $\mathrm{R} \& \mathrm{D}$ of new medicine are in short. Lots of peasant household lack special technique instruction. Technique talents in short make the whole Paris Yunnanensis industry lack the capability of developing to a higher level.

\section{COUNTERMEASURES FOR PROMOTING DEVELOPMENT OF PARIS YUNNANENSIS INDUSTRY}

The development of Paris Yunnanensis industry should insist the combination of resources protection and industry 
development and the combination of improving production and quality so as to develop Paris Yunnanensis industry better.

\section{A. More protection for Wild Paris Resource}

The development Paris Yunnanensis industry has to base on the rich resources, and should make area planning and implementation of plans carefully in accordance with distribution of Paris Yunnanensis resources. The combination of resource utilization and ecological protection has to be strengthened so as to form a technology-support system of sustainable utilization of resource. Not only the raw material supply of Paris has to be ensured, but also the wild resources of Paris have to be protected well. The government needs to strengthen the protection and guidance of wild Paris resources. Thus, the study and construction of planting wild Paris can be promoted, and the germ plasm advantage of Paris Yunnanensis can be ensured.

\section{B. Strengthening Market Supervision and Improving Products Quality Standard}

Plant source and process management of Paris has to be normalized from the origination. Pest control and prevention for Paris, and Paris production safety management have to be strengthened. Quality standard of all aspects like production place environment, raw material quality, foundation production has to be highlighted. The market access and supervision of Paris has to be strengthened, and market order has to be normalized so as to maintain order flow of Paris. Thus, the third rating standard for germ plasm resources of Paris can be established. Scientific classification of Paris has to be carried out, and detection standard for quality has to be improved. Study on eco-friendly planting technology and scale planting technology has to be focused on. Agricultural production insurance of Paris is encouraged to develop, and marketization dispersal mechanism of Paris production risks has to be constructed.

\section{Improving Organizational Degree of Paris Production}

Investment mechanism of project of risk sharing and benefit sharing has to be established. Industry association of Paris planting has to be established and accelerated so as to improve the organizational degree of Paris production. Head enterprises which possess advanced technology, strong power of core competitiveness, obvious products advantages, and strong driving effect have to be supported to carry out scale planting, standardized preparation, scientific production, and unified sale. Industrial chain system of Paris planting, preparation, processing, and sale can be integrated through establishing demonstrated Paris planting foundation and GMP to give play to the integration effect and play an exemplary role of the whole Paris industry. Production and processing of Paris as well as information communication, trading service, and industry connection between foundation and enterprises can be promoted by effective deployment and communication of resources and information as well as factor gathering, and creation of optimized industrial environment to ensure the effective supply of Paris resources.

\section{Strengthening Talent Training and Improving Industrial Technology Development Level}

Talent team construction needs to be accelerated, and highlevel talents have to be attracted actively. Reasonable distribution and free flow of talents between study institute and pharmaceutical enterprise have to be promoted. Expert talent pool for technology and innovation of Paris Yunnanensis industry needs to be established. Academic leader of Paris industry development has to be trained. Paris production at basement layer and technical training of circulation personnel have to be strengthened. In addition, field and online learning guidance for basic knowledge of Paris and normalized planting and breeding technology need to be carried out. Training of planting peasant household in technological aspects of selective breeding, normalized planting, processing in production place, and pest control and prevention has to be strengthened. Related government department should focus on the hi-tech talents training and introduction of gene study, planting and breeding, and pharmological study of Paris.

\section{E. Strengthening Paris Basic Study and Combination of Production and Study}

More investment for scientific research of Paris has to be strengthened. On the one hand, more attention has to be paid on Paris basic study. Chemical components of Paris are directly related to its therapeutic effects. Clear analysis on effects of all kinds of Paris resources can provide more medicinal resources for Chinese medicine. Basic study of management technology of superior seed breeding, nature, and planting and cultivation of Paris has to be strengthened. Selective breeding of Paris should be carried out and seedlings production of Paris should be accelerated so as to construct normalized and modern seedlings breeding foundation and germ plasm resources pool. Then, more attention has to be paid on the study of development and utilization of Paris overground part like stem and leaf. The development and application of massive products like food additive, feed additive, health product, cosmetics for special usage, and daily chemical product should also be intensified to avoid resources waste and alleviate the resourcesstrain problem.

\section{F. Persisting Eco-development and Accelerating Medicine and Edible Accreditation}

Security system of Paris quality has to be established and improved, and standardization system construction of Paris has to be strengthened. Quality certification for pollution-free Paris, green Paris, Paris organic product, Paris PGI, Paris registered trademark etc. should be promoted. In addition, comprehensive development and utilization for Paris resources of pharmaceutical enterprises need to be strengthened constantly. Research and development of new medical herb in pieces, health food, and new food raw material of Paris has to be carried out actively. Development of massive health industry of those which use Paris resources as raw material has to be focused on and expanded with persisting integration of "quality-nature-efficiency-application", and those industries includes raw material medicine, plant extract, drug intermediate, health product, and biological materials etc. Rehabilitation and health care industries of combination of 
Paris industry and Yunnan leisure tourism industry needs to be explored actively. Declaration for medicine and edible accreditation have to be carried out actively so as to let the Paris Yunnanensis resources which has already obtained medicine and edible accreditation get into supermarkets and retail outlets in food industry. Thus, marketing channels, market sales volume, and sales approach can be increased greatly and market risk can be decreased greatly.

\section{REFERENCES}

[1] HUANG Luqi, XIAO Peigen, WANG Yongyan. Investigation of Rare and Endangered Medicinal Plant Resources in China [M]. Shanghai Science and Technology Press, 2011.12:148-164.(In Chinese).

[2] Statistical Bulletin of National Economy and Social Development of Yunnan Province in 2014. http://finance.yunnan.cn/html/201502/27/content_3618018.htm.(In Chinese). 